\section{The facilitation of a new traction device (S-O clip) assisting endoscopic submucosal dissection for superficial colorectal neoplasms}

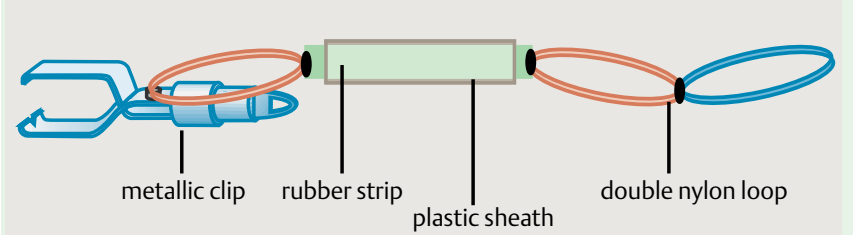

Fig. 1 The S-O clip consists of a metallic clip attached by a nylon line to the edge of a plastic sheath, which is coated with a rubber

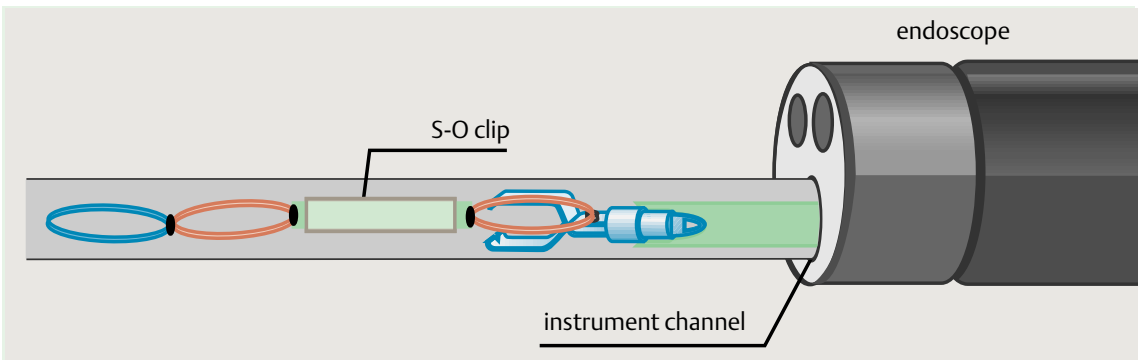

Fig. 2 The S-O clip can be passed through the instrument channel $(2.8 \mathrm{~mm}$ diameter) of the endoscope.

Endoscopic submucosal dissection (ESD) is a recently developed technique, but it is not widely used to treat the colorectum because of its degree of technical difficulty. It is possible that traction of the lesion may facilitate correct visualization of the lesion and make it easier to dissect. Several techniques involving lesion traction have been reported [1-4]. However, these methods have not been widely employed to date due to difficulty in both lesion fit and ease of use. We therefore designed a new traction device, the "S-O clip (Sakamoto-Osada clip)", for ESD.

The S-O clip consists of a metallic clip attached by a nylon line to the edge of a plastic sheath, which is coated with a rubber strip ( $10 \mathrm{~mm}$ long and $1.5 \mathrm{~mm}$ wide) and connected to a double nylon loop at the other end ( $\bullet$ Fig. 1 ). The S-O clip can be passed through the instrument channel of the endoscope ( $\odot$ Fig. 2). After partially dissecting the submucosa of the tumor, the S-O clip connects to the edge of the exfoliated mucosa $(\bullet$ Fig. 3 a) and the colonic wall opposite the lesion. This results in pulling the lesion up and opening the resection margin $(\bullet$ Fig.3b). After the dissection, the nylon loop is cut using the loop cutter $(\bullet$ Fig. 3c). There is no need to withdraw the endoscope during the procedure described. Finally, the specimen is brought out using the forceps.

ESD using the S-O clip has been performed on five superficial colorectal lesions. En bloc resection was achieved in all five cases without complication. The mean size of the resected lesions was $27.4 \mathrm{~mm}$ (range $22-42 \mathrm{~mm}$ ), and the procedure time was 75.4 minutes (range 38 110 minutes). We confirm that fitting the lesion with the S-O clip was easy and took only a few minutes (mean 2.5 minutes), and that the device facilitated both correct visualization and easier dissection of the tumor.

These preliminary results suggest that S-O clip-assisted ESD is effective, straightforward, and safe for the complete removal of large superficial colorectal neoplasms at any site of the colon (๑ Fig. 4).

Endoscopy_UCTN_Code_TTT_1AQ_2AD

N. Sakamoto, T. Osada, T. Shibuya, K. Beppu, K. Matsumoto, Y. Shimada, A. Konno, A. Kurosawa, A. Nagahara, T. Ohkusa, T. Ogihara, S. Watanabe Department of Gastroenterology, Juntendo University School of Medicine, Tokyo, Japan

\section{References}

1 Saito Y, Emura F, Matsuda Tet al. A new sinker-assisted endoscopic submucosal dissection for colorectal tumors. Gastrointest Endosc 2005; 62: 297-301

2 Kondo H, Gotoda T, Ono $\mathrm{H}$ et al. Percutaneous traction-assisted EMR by using an insulation-tipped electrosurgical knife for early stage gastric cancer. Gastrointest Endosc 2004; 59: 284-288

3 Kobayashi T, Gotohda T, Tamakawa $\mathrm{K}$ et al. Magnetic anchor for more effective endoscopic mucosal resection. Jpn J Clin Oncol 2004; 34: $118-123$

4 Imaeda $\mathrm{H}$, Iwao $\mathrm{Y}$, Ogata $\mathrm{H}$ et al. A new technique for endoscopic submucosal dissection for early gastric cancer using an external grasping forceps. Endoscopy 2006; 38: $1007-1010$

\section{Video 1}

We carried out endoscopic submucosal dissection with the S-O clip for laterally spreading tumors-nongranular type in the transverse colon.

Table 1 Endoscopic submucosal dissection with the SO-clip

\begin{tabular}{|c|c|c|c|c|c|c|c|}
\hline Patient $^{\mathrm{a}}$ & Age, years & Formation & Size,mm & Location & $\begin{array}{l}\text { Procedure time, } \\
\text { minutes }\end{array}$ & Pathologic findings & Depth of lesion \\
\hline 1 & 56 & LST-NG & 25 & Transverse colon & 54 & Tubular adenoma & \\
\hline 2 & 57 & LST-NG & 42 & Transverse colon & 110 & $\begin{array}{l}\text { Well differentiated } \\
\text { adenocarcinoma }\end{array}$ & $\mathrm{sm} 2$ \\
\hline 3 & 59 & LST-NG & 23 & Transverse colon & 75 & $\begin{array}{l}\text { Well differentiated } \\
\text { adenocarcinoma }\end{array}$ & $\mathrm{m}$ \\
\hline 4 & 62 & LST-NG & 22 & Ascending colon & 38 & Tubular adenoma & \\
\hline 5 & 58 & LST-NG & 25 & Rectum (Rb) & 100 & $\begin{array}{l}\text { Well differentiated } \\
\text { adenocarcinoma }\end{array}$ & $\operatorname{sm} 1$ \\
\hline
\end{tabular}




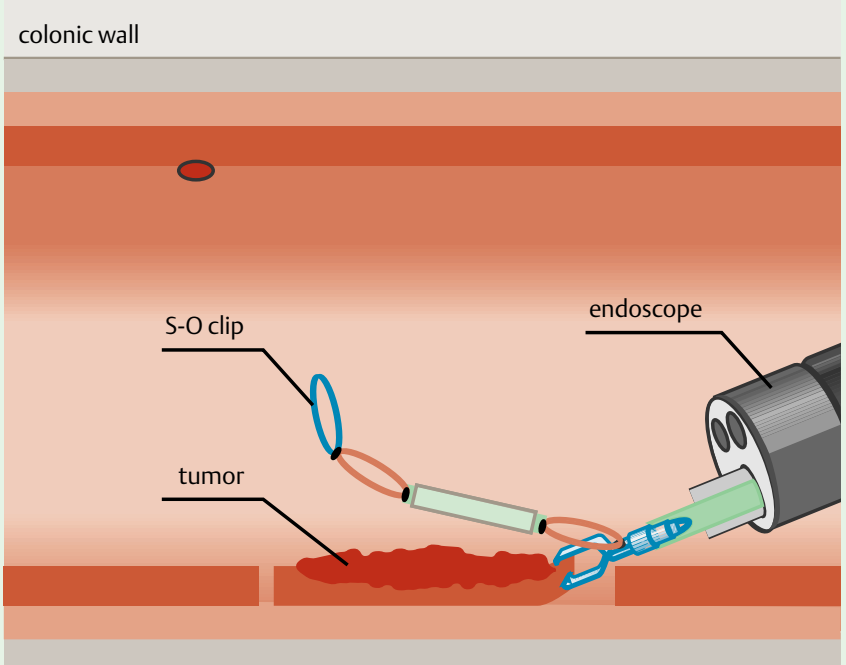

a

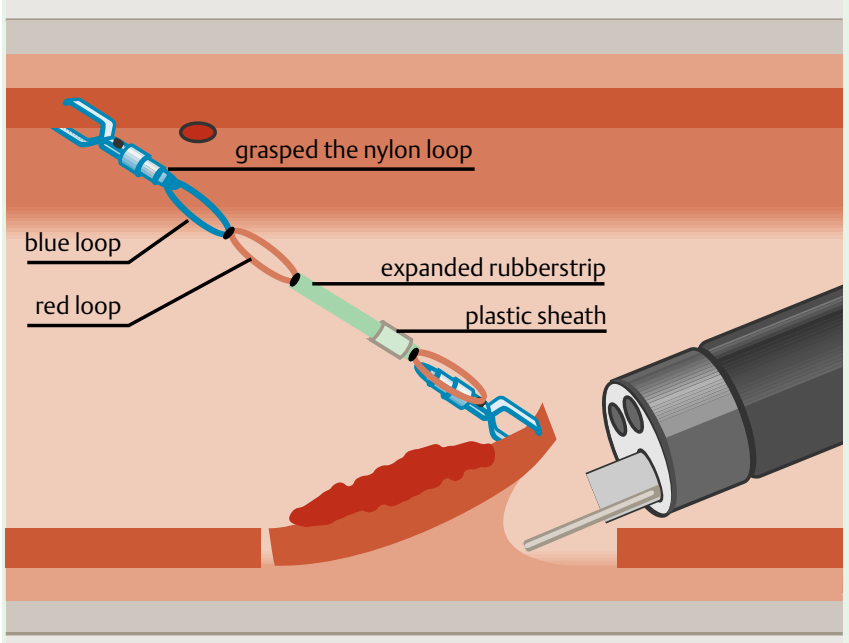

b

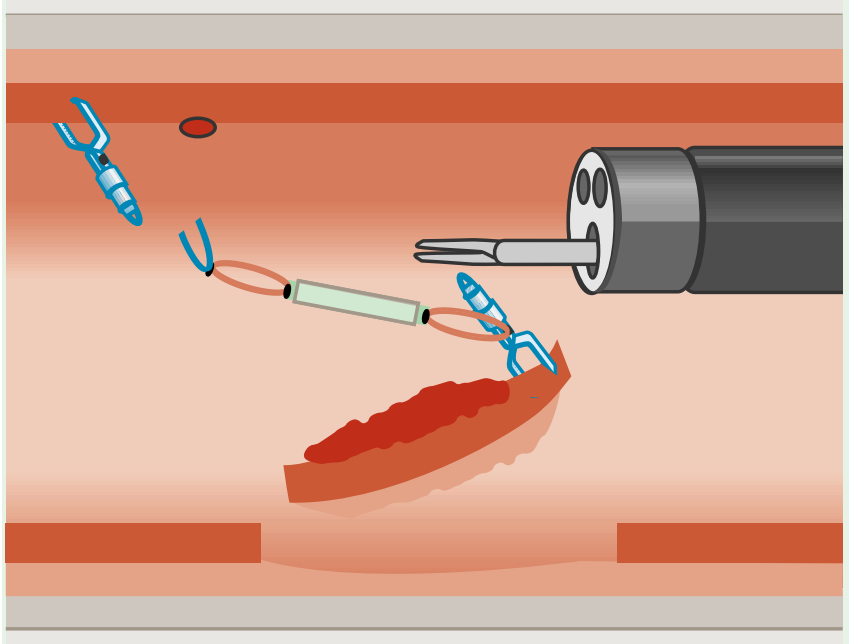

Fig. 3 Using the S-O clip. a After partially dissecting the submucosa of the tumor, the $\mathrm{S}-\mathrm{O}$ clip is applied to the edge of the exfoliated mucosa.

b A standard clip was then inserted and was applied to the colonic wall after having first grasped the distal nylon loop attached to the S-O clip. The standard clip was usually applied in a position opposite the lesion, enabling traction and therefore opening of the resection margin. c After endoscopic submucosal dissection, the nylon loop was cut by the loop cutter and brought out from the colon using the forceps.

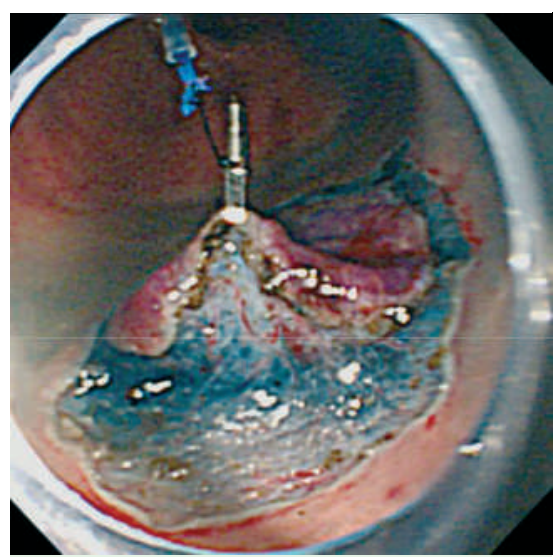

Fig. 4 A laterally spreading tumor (Case 5). After partially dissecting the submucosa of the tumor, traction of the lesion by the S-O clip facilitated correct visualization and easier dissection.

\section{Bibliography}

DOI $10.1055 / \mathrm{s}-2007-995603$

Endoscopy 2008; 40: E94-E95

(c) Georg Thieme Verlag KG Stuttgart · New York . ISSN 0013-726X

\section{Corresponding author}

\section{S. Watanabe, MD}

Department of Gastroenterology Juntendo University School of Medicine 2-1-1 Hongo Bunkyo-ku Tokyo 113-8421

Japan

Fax: +81-3-38138862

sumio@med.juntendo.ac.jp 